\title{
OPTIMALISASI PROSES BIOREMEDIASI SECARA IN SITU PADA LAHAN TERCEMAR PESTISIDA KELOMPOK MANKOZEB
}

\author{
SETIYO, Y., MADE S. UTAMA, WAYAN TIKA, DAN IBP. GUNADNYA \\ Program Studi Teknik Pertanian Fakultas Teknologi Pertanian, Universitas Udayana \\ E-mail: setiyoyohanes@yahoo.com
}

\begin{abstract}
ABSTRAK
Kompos sebagai pupuk organik dapat meningkatkan karakteristik fisik, kimia, dan biologi dari tanah dengan cara dapat menyediakan mineral tanah untuk tanaman. Tujuan khusus dari penelitian ini adalah untuk mengoptimalkan proses bioremediasi untuk mendegradasi residu pestisida di Bedugul Agro-Tourism sehingga sistem pertanian organik akan terjaga. Berdasar pada $C / N$, dan pH, dapat menghasilkan solusi yang lebih baik untuk bioremediasi masalah residu pestisida dilakukan dengan mencampurkan kompos dalam pemeliharaan koltikultura. Penyimpangan $p H$ dalam proses bioremediasi sebesar 0.22, dan pH proses bioremediasi in-situ antara 6.9 dan 7.12 atau pH netral. Pada kondisi ini mikroorganisme akan efektif mengurangi residu pestisida. Proses bioremediasi pada residu pestisida Ditane M-45 pada pemeliharaan holtikultura dibagi menjadi $1.2 \mathrm{~g} / \mathrm{l} / 20 \mathrm{~m}^{2}, 2.4 \mathrm{~g} / \mathrm{l} / 20 \mathrm{~m}^{2}$, dan $3.6 \mathrm{~g} / \mathrm{l} / 20 \mathrm{~m}^{2}$ disebar di area secara sempurna, di mana terlihat dari parameter-parameter akan perkembangan populasi mikroorganisme dan jumlah dari residu pestisida. Residu pestisida untuk setiap dosis adalah 0.25-1.7\% pada 35 hari atau nilai ini di bawah 0.003 ppm.
\end{abstract}

Kata kunci: residu pestisida, kompos campuran, proses bioremediasi

\begin{abstract}
Compost as an organic fertilizer could improve the physical, chemical, and biological characteristics of the soil in a certain way so that soil mineral was available for plant. The special aim of this research was to optimize the bioremediation process for degradation of pesticide residues at Bedugul Agro-tourism so that organic farming system will be sustainable. Based on $\mathrm{C} / \mathrm{N}$, and $\mathrm{pH}$, it could be concluded that better solution for bioremediation of pesticide residue problem was by giving mixed-compost in horticulture cultivation. Deviation of $p H$ in bioremediation process was 0.22 , and $p H$ in-situ bioremediation process was between 6.9 and 7.12 or neutral pH. In this condition micro-organism would be effective in degrading pesticide residue. Bioremediation process on pesticide residue of Ditane $M-45$ at horticulture cultivation deploy with $1.2 \mathrm{~g} / \mathrm{l} / 20 \mathrm{~m}^{2}, 2.4 \mathrm{~g} / \mathrm{l} / 20 \mathrm{~m}^{2}$, and $3.6 \mathrm{~g} / \mathrm{l} / 20 \mathrm{~m}^{2}$ spraying dosages took place perfectly, which was showed by parameters on development of micro-organism population and the amount of pesticide residues. Pesticide residue of each spraying dosages was $0.25-1.7 \%$ at 35 days or this values were under 0.003 ppm.
\end{abstract}

Key words: pestiside residue, mixed compost, bioremediation process

\section{PENDAHULUAN}

Bioremediasi in situ menggunakan pupuk organik kompos sangat efektif, hasil penelitian Indrayani (2006) mikroorganisme pada kompos mampu mendegradasi residu pestisida dalam tanah pada proses bioremediasi secara ex-situ. Selain itu kompos mampu memperbaiki sifat fisik tanah (Setiyo, 2009), sifat biologis dan sifat kimia tanah untuk peningkatan kesuburan tanah (Pare et al., 1999; Kondo dan Yasuda, 2003).

Penggunaan pestisida dalam produksi buah dan sayur di kawasan wisata Bedugul tidak dapat dihindarkan. Hal ini dilakukan agar gagal panen dapat direduksi dan petani tetap meraih keuntungan maksimal. Dampak negatip dari aktivitas ini adalah (1) buah dan sayur masih mengandung pestisida,
(2) ekosistem di lahan pertanian tercemar, (3) dan ekosistem perairan di danau Buyan tercemar. Proses bioremediasi secara ex situ untuk lahan yang luas menjadi kendala, kendala utama adalah tidak mungkin mengangkut tanah dalam jumlah ratusan ton ke laboratorium, sehingga pemberian kompos ke lahan lebih memungkinkan.

Hasil yang ditargetkan adalah model proses bioremediasi menggunakan kompos untuk menurunkan tingkat pencemaran lahan pertanian yang disemprot pestisida Dithane M-25 sebagai upaya mempertahankan sistem pertanian organik berkelanjutan (sustainable organic farming system) dan hortikultura yang berkualitas Pemupukan lahan pertanian menggunakan kompos menurut Reijntjes et al. (1999) merupakan pengembangan sistem 
pertanian dengan input luar rendah dan sistem sangat efektif.

\section{METODE}

Lahan pertanian yang dibudidayakan tanaman wortel, sawi, strowberi, dan tomat diberi pupuk kompos kotoran sapi atau tanpa dipupuk kompos (sebagai kontrol) dan pada saat tanaman berusia 1 bulan disemprot pestisida Ditane M-45 dengan konsentrasi $1.2 \mathrm{~g} / \mathrm{l} / 20 \mathrm{~m}^{2}$ (dosis redah), $2.4 \mathrm{~g} / \mathrm{l} / 20$ $\mathrm{m}^{2}$ (dosis sedang), dan $3.6 \mathrm{~g} / \mathrm{l} / 20 \mathrm{~m}^{2}$ (dosis tinggi). Perkembangbiakan bakteri dan kapang diamati pada sampel tanah yang diambil pada kedalaman $0 \mathrm{~cm}$, 0-5 cm dan 5-10 cm, selain itu diamati pula konsentrasi residu pestisida dan kandungan C-organik dan $\mathrm{N}$ organik. Sampel tanah diambil $0,2,4,7,15,30,45$, dan 60 hari setelah waktu penyemprotan pestisida.

Analisis populasi bakteri dilakukan dengan metode TPC pada media PCA. Pembuatan PCA dengan melarutkan $15 \mathrm{~g}$ agar, $1 \mathrm{~g}$ dextrosa, 5 tripton, $1.5 \mathrm{~g}$ yeast ke dalam $1000 \mathrm{ml}$ aquadest. Larutan tersebut dipanaskan sambil diaduk dengan magnetic stirer sampai mendidih dan homogen. Selanjutnya larutan disterilisasi dalam autoclave pada suhu $121^{\circ} \mathrm{C}$ selama 15 menit. Setelah agak dingin dituangkan ke dalam cawan petri steril $\pm 15-20 \mathrm{ml}$ dan didinginkan. Setelah padat cawan petri ditutup dalam posisi terbalik.

Metode TPC dilakukan dengan melarutkan 1 g sampel dengan $9 \mathrm{ml} \mathrm{NaCL}$ faali $(0.9 \%)$ ke dalam tabung reaksi. Larutan ini pengencerannya $10^{-1}$ dan pengenceran dilakukan sampai $10^{-6}$. Setiap kali melakuan pengenceran larutan diaduk menggunakan vortek. Selanjutnya $0.1 \mathrm{ml}$ larutan untuk pengenceran $10^{-4}$ sampai $10^{-6}$ dituang ke media PCA menggunakan ependorf dari stip steril. Selanjutnya larutan disebar dengan sprider yang telah dicelupkan pad alkohol dan dipanaskan. Kemudian diinkubasi pada suhu ruang selama 48 jam. Koloni yang dihitung hanya yang berjumlah 30-300 koloni.

Ekstraksi sampel dilakukan secara langsung. Pengujian dengan Gas Kromatografi, di awali dengan penyaringan, pemurnian dan injeksi ke dalam kolom. Pada proses penyaringan, sampel tanah ditimbang sebanyak 250 gram dan ditambahkan Acetonitril serta 5 gram $\mathrm{Na}_{2} \mathrm{SO}_{4}$ anhidrat granuler, kemudian diblender dan disaring. Proses selanjutnya adalah memasukkan sebanyak $93 \mathrm{ml}$ filtrat dalam corong pisah yang berisi $100 \mathrm{ml}$ petroleum eter, dikocok selama 5 menit, dan membuang lapisan air yang terpisah pada bagian bawah. Pada sisa larutan ditambahkan $200 \mathrm{ml} \mathrm{Na}_{2} \mathrm{SO}_{4} 2 \%$, dikocok selama 2 menit, dan membuang lagi sisa air yang terpisah.
Pada corong biasa diberi glass wall dan $\mathrm{Na}_{2} \mathrm{SO}_{4}$ anhidrat granuler pada lapisan atas, dilewatkan pada corong untuk disaring. Proses selanjutnya adalah pemurnian. Pada proses pemurnian, glass wall ditempatkan pada bagian bawah kolom kromatografi dan ditambahkan 1.6 gram fluoricyl serta 1.6 gram $\mathrm{Na}_{2} \mathrm{SO}_{4}$ anhidrat Granuler, kolom dicuci dengan $50 \mathrm{ml}$ heksan, kemudian dengan 50 $\mathrm{ml}$ metanol, dan membuang cairan pencuci. Elusi dengan $11 \mathrm{ml}$ heksan, ditampung masing-masing dalam labu erlemeyer dan diuapkan sampai $0.5 \mathrm{ml}$ diatas water bath. Sampel yang telah diuapkan diatas water bath diambil sebanyak 10 mikroliter dengan menggunakan syringe, kemudian di injeksikan ke dalam kolom melalui septum secara bersamaan dengan menekan tombol start. Dilayar monitor, diagram kromatogram yang terbentuk dapat dimati. Perhitungan nilai kuantitatif residu yang terdapat pada sampel menggunakan rumus:

$\mu \mathrm{g} / \mathrm{L}(\mathrm{ppm})=\frac{\mathrm{A} \times \mathrm{B} \times \mathrm{C} \times \mathrm{D}}{\mathrm{E} \times \mathrm{F} \times \mathrm{G}}$

Di mana:

A : Konsentrasi larutan standart pestisida $(\mu \mathrm{g} / \mu \mathrm{l})$,

B : Tinggi puncak hasil pemurnian ( $\mathrm{mm})$,

C : Volume akhir hasil ekstraksi $(\mu \mathrm{l})$,

D : Faktor Pengenceran,

E : Tinggi puncak larutan standart (mm),

$\mathrm{F}$ : Volume hasil pemurnian yang disuntikkan $(\mu \mathrm{l})$, dan

$\mathrm{G}$ : $\quad$ Volume atau berat dari contoh atau spesimen yang di ekstrak (ml atau gram).

Pengukuran kandungan C-oraganik dengan metoda AOAC 1995, dan pengukuran N-organik dengan metoda CHONS Analyser 1998. Sedangkan $\mathrm{pH}$ tanah diukur dengan pengambilan sampel tanah di kedalaman 0-5 cm dan 5-10 cm bersamaan dengan pengukuran $\mathrm{C}$-organik, $\mathrm{N}$-organik dan populasi mikroba.

\section{HASIL DAN PEMBAHASAN}

Penyemprotan pestisida pada tanaman hortikultura sawi, wortel, tomat, stroberi dan cabai pada lahan tidak dipupuk kompos menunjukkan bahwa residu lebih lambat teremediasi dibandingkan dengan residu pestisida pada lahan yang dipupuk dengan kompos. Peluang residu pestisida terbawa run off ke Danau Buyan untuk lahan pertanian tidak dipupuk kompos dari Gambar 1 adalah hampir 45 hari, sedangkan jika lahan dipupuk dengan kompos peluangnya hanya 7 hari. 


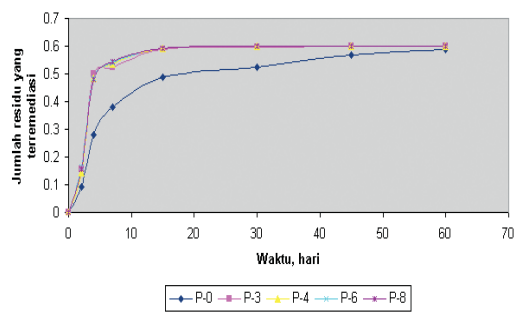

a. Dosis tinggi

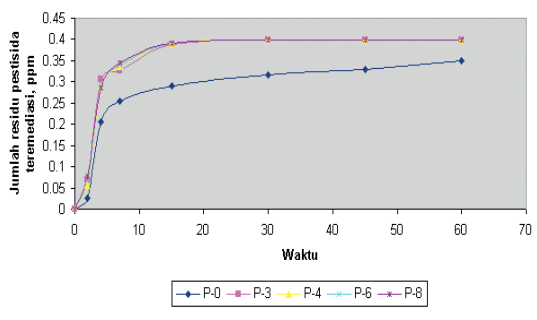

b. Dosis sedang

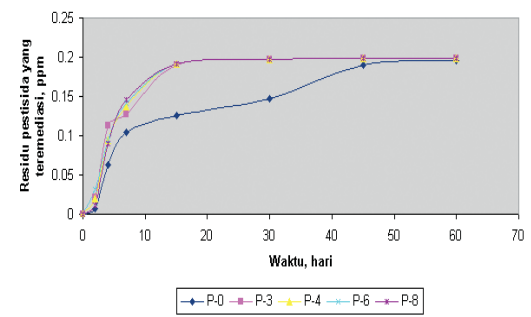

c. Dosis rendah

Gambar 1. Akumulasi resid in-situ dari penelitian di Kawasan Wisata Bedugul untuk perlakuan pemupukan dengan u pestisida teremediasi

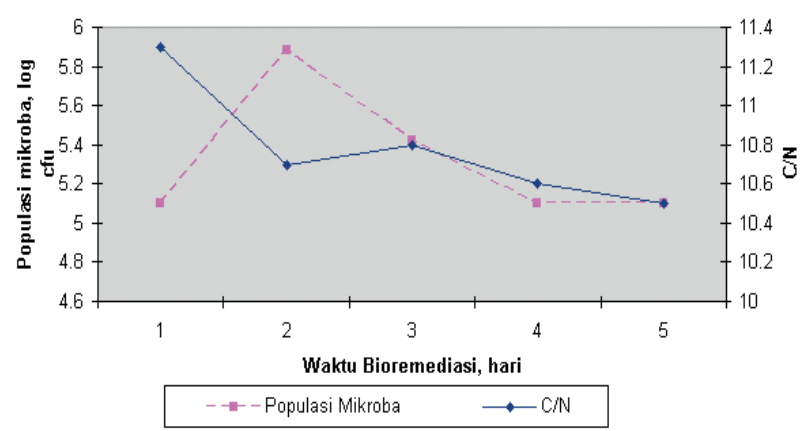

Perlakuan kompos kotoran sapi terfermentasi

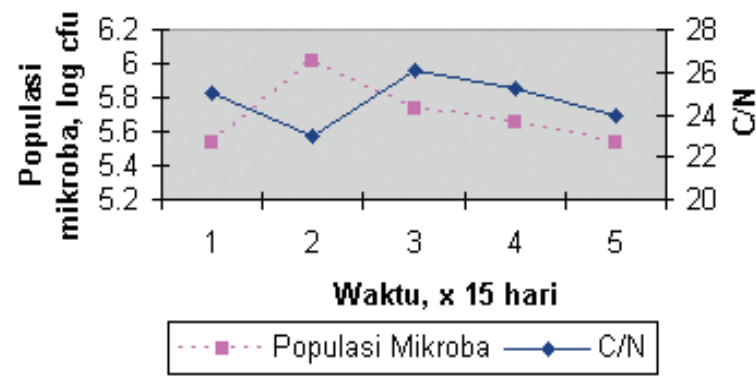

Perlakuan kompos sampah kota
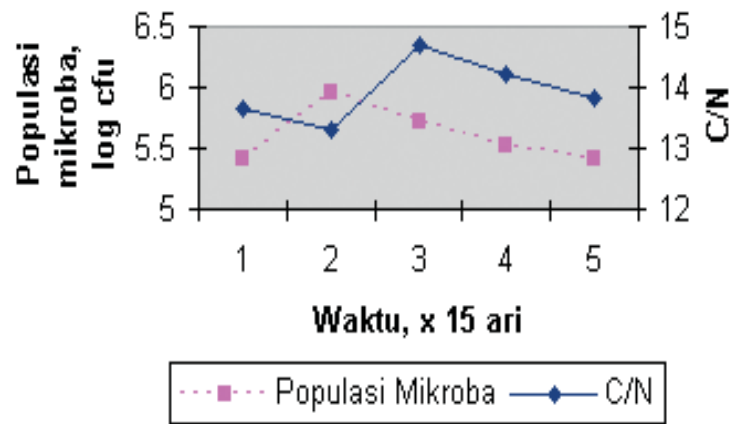

Perlakuan kompos bokasi

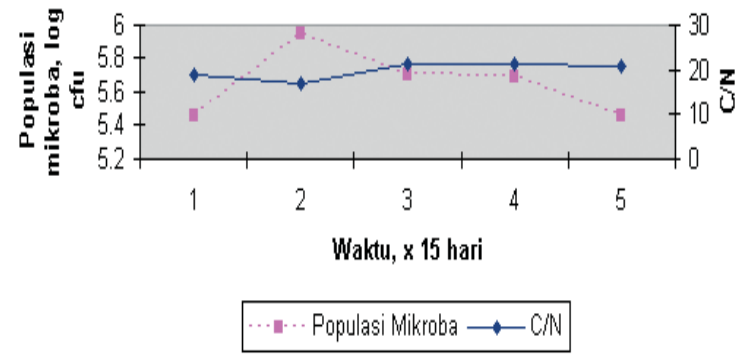

Perlakuan kompos campuran

Gambar 2. Hubungan waktu bioremediasi residu pestisida, populasi mikroba dan $\mathrm{C} / \mathrm{N}$ tanah

Nutrien pada proses bioremediasi pada lahan yang dipupuk kompos tersedia dalam bentuk bahan organik, residu tanaman dan residu pestisida. Namun nutrien pada lahan tidak dipupuk kompos hanya tersedia dalam bentuk residu tanaman, sehingga proses bioremediasi di lahan yang dipupuk kompos lebih cepat dibandingkan lahan yang tidak dipupuk kompos. Nutrien berupa pestisida di lahan oleh mikroba diurai untuk dijadikan bahan penyusun sel, (Cookson, 1995). Sedangkan menurut Vidali (2001) residu pestisida di lahan diremediasi secara aerobik ataupun anaerobik.

Dinamika populasi mikroba berhubungan erat dengan perubahan $\mathrm{C} / \mathrm{N}$ bahan organik, dinamika $\mathrm{C} /$ $\mathrm{N}$ dan populasi mikroba seperti Gambar 2. Kenaikan populasi mikroba di awal proses bioremediasi residu pestisida diikuti dengan penurunan $\mathrm{C} / \mathrm{N}$ tanah, hal ini disebabkan nutrien $\mathrm{C}, \mathrm{H}, \mathrm{O}, \mathrm{N}$ yang ada pada residu pestisida dan tanah diurai oleh mikroba untuk dimanfaatkan sebagai bahan penyusun selnya. Sedangkan, puncak populasi mikroba terjadi bersamaan dengan titik minimum $\mathrm{C} / \mathrm{N}$ tanah. Pada proses selanjutnya sebagian mikroba mati terurai menjadi unsur hara, unsur hara $\mathrm{C}$ dan $\mathrm{N}$ organik sebagian menaikan $\mathrm{C} / \mathrm{N}$ dan sebagian lagi diserap perakaran tanaman.

Fase menurunnya populasi mikroba dan menurunnya $\mathrm{C} / \mathrm{N}$ secara bersamaan disebabkan oleh suplai unsur hara untuk tanaman hortikultura dari mikroba yang mati belum cukup, sehingga tanaman mengambil unsur hara dari tanah. Hal inilah yang menyebabkan $\mathrm{C} / \mathrm{N}$ tanah mengalami penurunan. Dinamika populasi mikroba dan $\mathrm{C} / \mathrm{N}$ pada proses bioremediasi in-situ di Bedugul identik dengan penelitian Indrayani (2006). 
Hubungan antara populasi mikroba dengan $\mathrm{pH}$ tanah diilustrasikan seperti Gambar 3. Kenaikan pH di minggu pertama sampai minggu ke tiga, karena ada demineralisasi bahan organik terutama unsur mikro $\mathrm{Mg}^{2+}, \mathrm{K}^{+}, \mathrm{Ca}^{2+}$ dari kompos dan residu pestisida. Kation-kation ini akan berikatan dengan asam-asam yang terbentuk selama proses dekomposisi menyebabkan $\mathrm{pH}$ naik. Pada $\mathrm{pH}$ di atas 7 sifat massa yang didekomposisi cenderung basa, sehingga kelebihan ion $\mathrm{OH}^{-}$akan mengakibatkan kehilang ammonium dalam bentuk $\mathrm{NH}_{3}^{-}$dan hidrosilasi beberapa unsur biologis seperti $\mathrm{Cu}$ dan Mn membentuk campuran karbonat yang sulit terurai (Ton, 1991; Alexander, 1999; Semple et al. 2001; Singer and Crohn, 2002). Pada pH di bawah 7, sifat massa yang didekomposisi cenderung asam, sehingga kelebihan ion $\mathrm{H}^{+}$dapat menyebabkan penguraian dan pelepasan ion $\mathrm{Ca}^{2+}$ dan $\mathrm{Mg}^{2+}$ dari mikroorganisme, ion-ion metal dari mineral dan bahan organik (Sudyastuti, 2007) .

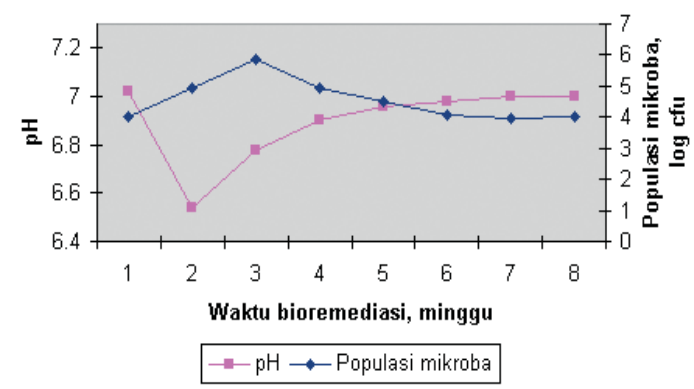

\section{Perlakuan Kontrol}

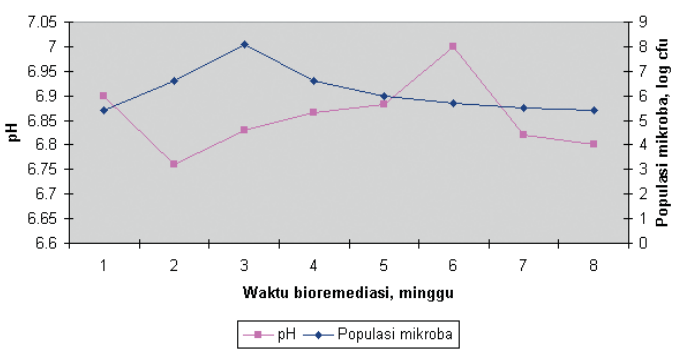

Perlakuan kompos bokasi
Proses bioremediasi in-situ lahan tercemar pestisida Dithane M-45 yang disemprot dengan dosis rendah, menunjukan bahwa reaksi bioremediasi berlangsung pada $\mathrm{pH}$ mendekati netral. Dari identifikasi di lapangan memang tidak ada bau terdeteksi dari indera penciuman, sehingga pelepasan gas $\mathrm{NH}_{3}$ penyebab bau tidak terjadi, al ini sesuai dengan hasil penelitian Indrayani (2006) untuk proses bioremediasi ex-situ. Reaksi bioremediasi yang berlangsung pada $\mathrm{pH}$ sedikit asam adalah perlakuan kontrol, disebabkan karena pelepasan unsur-unsur seperti $\mathrm{Mg}^{2+}, \mathrm{K}^{+}, \mathrm{Ca}^{2+}$ dari kompos tidak ada.

Pada perlakuan pemupukan dengan kompos campuran, perubahan $\mathrm{pH}$ hanya 0.22 dan $\mathrm{pH}$ medium pada keadaan netral, sehingga mikroba akan lebih efektif meremidiasi residu pestisida. Perlakuan ini adalah perlakuan terbaik.

Hubungan residu pestisida dengan waktu bioremediasi untuk kedalaman tanah 0-5 cm seperti Gambar 4. Perlakuan kontrol untuk dosis

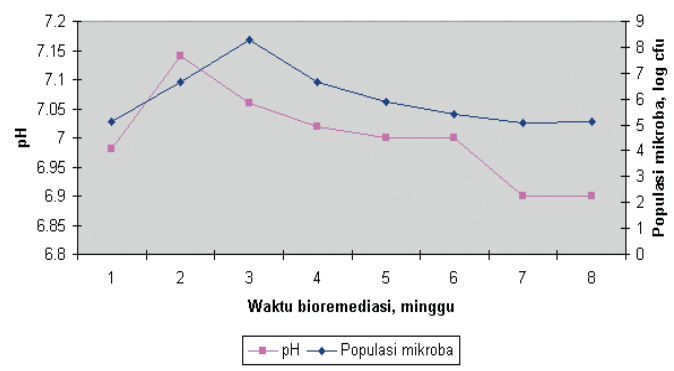

Perlakuan kompos kotoran sapi terfermentasi

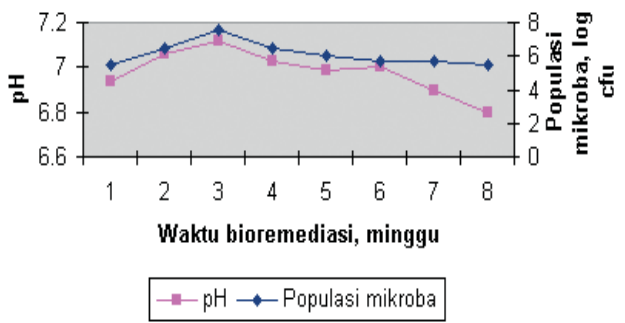

Perlakuan kompos sampah kota

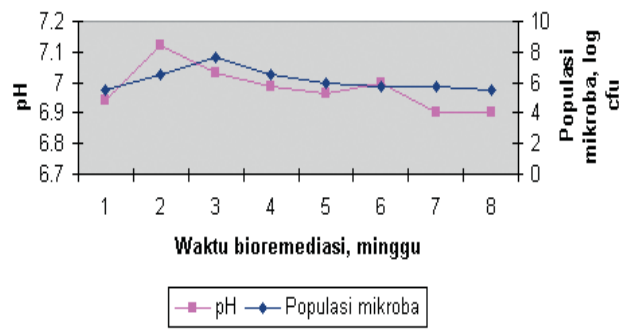

Perlakuan kompos campuran

Gambar 3. Hubungan Waktu Bioremediasi, $\mathrm{pH}$ dan populasi mikroba pada proses bioremediasi in-situ 


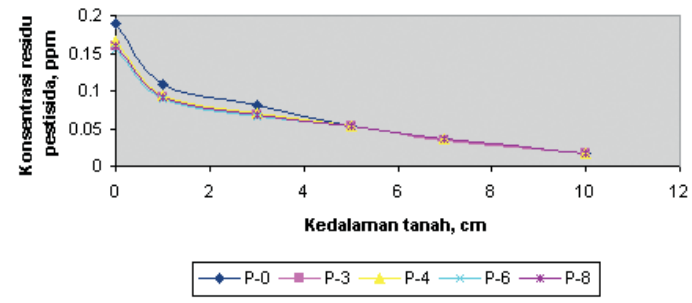

Penyemprotan dosis rendah

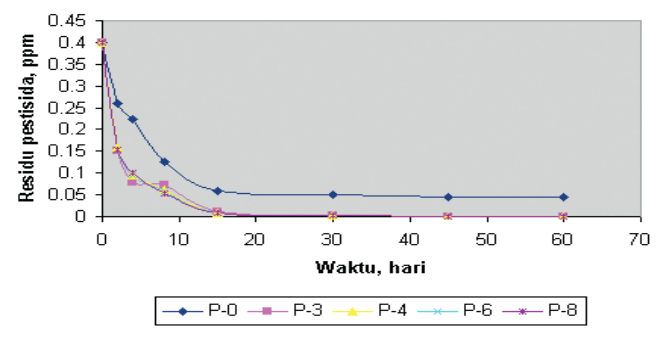

Penyemprotan dosis sedang

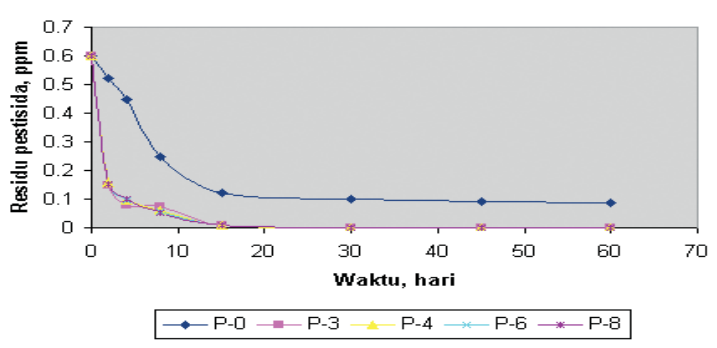

Penyemprotan dosis tinggi

Gambar 4. Jumlah residu pestisida yang teremediasi

penyemprotan dosis rendah, residu pestisida hampir habis di minggu ke 6 , sedangkan untuk dosis sedang dan dosis tinggi masih menyisakan residu di lahan sampai hari ke 60. Pada penyemprotan dosis sedang dan dosis tinggi, jumlah residu pestisida yang masuk ke zona perakaran lebih banyak sehingga proses bioremediasi memerlukan waktu lebih panjang.

Hubungan antara konsentrasi residu pestisida pada kedalaman $0-5 \mathrm{~cm}$, dan $5-10 \mathrm{~cm}$ pada dosis penyemprotan sedang dan dosis tinggi dengan populasi mikroba digambarkan pada Gambar 4 . Residu pestisida dari perlakuan pemberian pada lahan dengan dosis 12 ton per ha pada minggu ke 5 tersisa antara $0.25-1.7 \%$ atau dibawah $0.003 \mathrm{ppm}$.

Perlakuan terbaik adalah perlakuan pemberian kompos campuran, perlakuan ini pada minggu ke 5 dari dosis penyemprotan tinggi menyisakan residu $0.25 \%$ atau $0.0015 \mathrm{ppm}$. Populasi mikroba di awal bioremediasi, jumlah nutrien pada kompos, porositas kompos, kelengasan tanah, suhu dan $\mathrm{pH}$ tanah mendukung proses bioremediasi residu pestisida secara optimal.

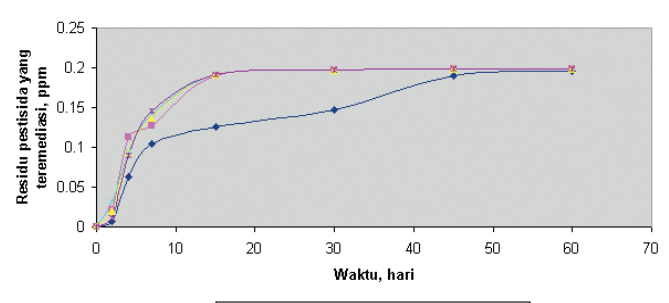

$\rightarrow-\mathrm{P}-0 \rightarrow-\mathrm{P}-3-\mathrm{P}-\mathrm{P}-4 \rightarrow \mathrm{P}-6 \rightarrow-\mathrm{P}-8$

Penyemprotan dosis rendah

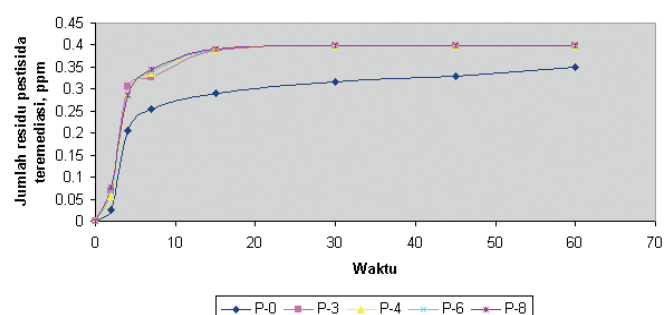

Penyemprotan dosis sedang

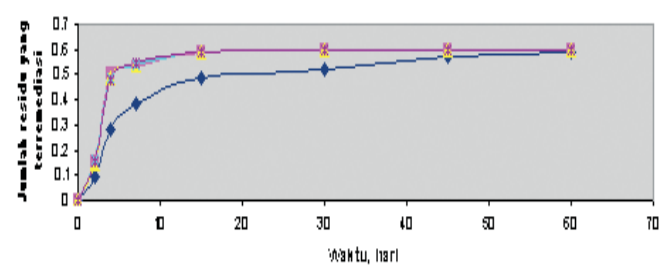

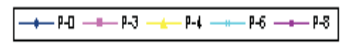

Penyemprotan dosis tinggi

\section{SIMPULAN}

Berdasarkan dinamika $\mathrm{pH}$, populasi mikroba dan $\mathrm{C} / \mathrm{N}$ tanah proses bioremediasi residu pestisida secara in-situ pada lahan budidaya hortikultura di Kawasan Wisata Bedugul berlangsung secara optimal. Perlakuan pemupukan dengan kompos campuran memberikan reaksi bioremediasi dengan perubahan $\mathrm{pH}$ hanya 0.22 dan reaksi pada kondisi $\mathrm{pH}$ netral, sehingga mikroba akan lebih efektif meremidiasi residu pestisida. Residu pestisida dari masingmasing dosis penyemprotan pada hari ke 35 tersisa $0.25 \%-1.7 \%$ atau dibawah $0.003 \mathrm{ppm}$. Dari identifikasi awal kelompok aktinomisetes mendominasi proses bioremediasi pada saat kelengasan tanah di bawah $30 \%$, dan kelompok bakteri mendominasi proses pada kelengasan tanah di atas $30 \%$.

\section{DAFTAR PUSTAKA}

Alexander, M. 1999. Biodegradation and Bioremediation. Second Edition. Academic Press. London. 
Cookson, J.T. 1995. Bioremediation Engineering: Design and Aplication. Mc Graw Hill. Inc. Toronto.

Indrayani, N. 2006. Bioiremediasi lahan tercemar profenofos secara ex-situ dengan cara pengomposan. [Thesis\}. Bogor: Sekolah Pasca Sarjana, Institut Pertanian Bogor

Kondo M and Yasuda M. 2003. Effects of temperature, water regime, light, and soil properties on $\mathrm{N}_{2}$ fixation associated with decomposition of organic mater in paddy soils. JARQ 37(2): 113-119.

Pare T, Dinel H, and Schnitzer M. 1999. Extractability of trace metals during co-composting of biosolids and municipical solid wastes. J. Biol. Fertil. Soils 29: 31-37.

Reijntjes, C; B Harverkort and Ann Waters B., 1999. Pertanian Masa Depan. Pengantar Untuk Pertanian Berkelanjutan dengan Input Luar Rendah. Penerbit Kanisius. Yogyakarta.

Semple, K.T., B.J. Reid, and T.R. Fermor. 2001. Impact of composting strategies on the treatment of soil contaminated with organic pollutant. Reviw. Environmental Pollution 112: 269-283.
Setiyo, Y., Suparta U., Tika W., dan Gunadya, IBP. 2009. Pengembangan Model Bioremediasi Menggunakan Kompos Pada Lahan Tercemar Untuk Meningkatkan Kualitas Produk Hortikultura (Studi Kasus: Kawasan Agrowisata Bedugul-Bali). Laporan Penelitian Hibah Kompetitif Sesuai Strategis Nasional.

Singer, A.D., and Crohn. 2002. Persistence and Degradation of Pesticides in Composting California Integrated Waste Management Board (CIWMB). California,

Sudyastuti, T dan Setyawan, N. 2007. Sifat thermal tanah pasiran pantai dengan pemberian bahan pengkondisi tanah dan biomikro pada budidaya tanaman cabai (capsicum annuum). Prosiding seminar nasional teknik pertanian - Yogyakarta.

Ton, S.W., 1991. Environmental Considerations With Use of Pesticides in Agriculture. Paper pada Lustrum Regulations. University of Minnesota.

Vidali, M. 2001. Bioremediation. Pure Appl. Cem. 73: 1163-1172. 